\title{
Adaptación y legitimación: el aprovechamiento del material histórico en Felipe Ángeles, de Elena Garro
}

\section{Adaptation and Legitimation: the Use of Historical Material in Elena Garro's Felipe Ángeles}

\author{
Jesús Manuel Gamboa Valles \\ Universidad Autónoma de Ciudad Juárez \\ jesus.gamboa87@yahoo.com
}

RESUMEN: El tema de este artículo es el aprovechamiento del material histórico en el drama Felipe Ángeles, y la manera en la cual esta pieza ha contribuido a la legitimación de ciertas facetas históricas del caudiIlo. El análisis se desarrolla en tres partes: la primera consiste en la recuperación de las diversas imágenes Palabras clave: política; drama histórico; legitimación; Revolución mexicana del caudillo, divulgadas a partir de la historiografía, la prensa y algunas obras literarias cercanas a la época; la siguiente es una revisión panorámica acerca de su proceso de escritura y, finalmente, la tercera aborda la teatralidad política desplegada en el juicio sumario, mediante sus correspondencias y diferencias con el texto taquigráfico original.

KEYWORDS:

Politics;

Historical drama;

Legitimation;

Mexican Revolution.
ABSTRACT: The theme of this article is the use of historical material in the drama Felipe Ángeles, and the way in which this piece has contributed to the legitimation of certain historical facets of the leader. The analysis is developed in three parts: the first is to recover the many images of the dictator, printed on historiographical works, the press and some literary works of that time; the next is a panoramic review of his writing process and, finally, the third deals with the political theatricality displayed in summary judgment, through correspondence and differences with the original shorthand text. 


\section{Introducción}

Resulta evidente que la recuperación de todo hecho histórico está condicionada tanto por la formación cultural y preferencias individuales del historiador como por el espacio desde el cual escribe, los códigos interpretativos de una época y el predominio de un discurso hegemónico específico. En consecuencia, la disposición y el papel de sus protagonistas también se verán necesariamente afectados.

Adam Schaff, por ejemplo, reflexiona sobre cuatro puntos cardinales de la historia como ciencia: qué son los hechos históricos, cómo se explican o valoran, qué se entiende por "objetividad" y cuál es la razón de que se reescriban continuamente (244). A diferencia de la escuela de Leopold von Ranke y su enfoque positivista, ${ }^{1}$ Schaff observa que la historiografía posterior al siglo XIX concibe al entramado histórico no como "hechos puros", fijos y universales (idiografismo), sino como producto de una selección y una elaboración necesariamente valorativa. Estos cortes y segmentación de los materiales implicarán, por definición, un sujeto concreto responsable y un sistema de referencia ideológico y cultural a partir del cual se llevará a cabo el proceso de transmisión (253). ${ }^{2}$

En consecuencia, apunta Schaff, todo trabajo histórico nos presenta una visión específica, condicionada por la propia voluntad del historiador y el contexto cultural desde el que se emite (274-275). El resultado, entonces, se expresará en una disparidad, cuando no en una patente confrontación, entre las perspectivas de diferentes estudiosos con respecto a un periodo determinado, toda vez que algunos episodios serán considerados relevantes y otros no: "La interpretación es, pues, la que eleva los hechos ordinarios al rango de los hechos históricos o derriba a éstos de su pedestal" (281). ${ }^{3}$

1 Para una revisión panorámica tanto de la historiografía del siglo XIX como del papel que Ranke tuvo en el nacimiento del historicismo, véase el trabajo de Rebeca Villalobos (2007).

2 Una propuesta similar se encuentra en Michel de Certeau, cuando explica cómo el historiador escribe no en virtud de significados externos, sino a partir de una "filosofía particular" — subjetividad del autor-y un "lugar" —instituciones, sociedades, épocas específicas-, los cuales determinan su "hacer" (1993: 69-79).

${ }^{3}$ Para una visión más amplia de la inclusión y exclusión de hechos históricos en función de un discurso imperante, véase Iggers 1995: 18. 
El caso de Felipe Ángeles es un claro ejemplo, incluso sintomático, de cómo un mismo personaje histórico puede adquirir valores diferentes a lo largo del tiempo. ${ }^{4}$ Figura ambigua y ciertamente peculiar dentro de ese "teatro de los acontecimientos" que fue la Revolución mexicana, biógrafos e historiadores resaltan su cercanía con Villa, el empleo de sus dotes intelectuales, el manejo, en sus discursos, de una concepción ética sobre la guerra y su idea del sacrificio como manifestación de una causa elevada. Estos elementos, aprovechados mucho tiempo después en la conformación de un discurso tipificador del "héroe revolucionario", 5 marcan la pauta para establecer un doble inventario de imágenes: las que retratan a un reaccionario o un traidor de carácter más bien voluble y sin resoluciones políticas claras; y aquellas que expresan a un hombre de altos ideales, un consejero solitario, el conciliador de las fracciones revolucionarias o el prototipo trágico del héroe.

Con base en esta convivencia paradójica de elementos biográficos, alusiones históricas y reconstrucciones literarias, el objetivo del presente trabajo es demostrar que Elena Garro, en su afán por reivindicar el nombre

\footnotetext{
${ }^{4}$ Pese a que mi intención es bosquejar un perfil lo más completo posible sobre Ángeles, trazo aquí la biografía que suele aparecer en la mayor parte de las enciclopedias, revistas de divulgación, libros conmemorativos y diccionarios electrónicos: Felipe de Jesús Ángeles Ramírez nació el 13 de junio de 1868 en Zacualtipán, Hidalgo. Hijo de un militar que estuvo al servicio de Porfirio Díaz durante la Intervención estadounidense, estudia en el Colegio Militar de Chapultepec, de donde egresa en 1892. En 1909, apoyado por el propio Díaz, viaja a Francia para conocer las nuevas formas de tiro. Tras dos años en el extranjero, regresa a México, nombrándolo Madero director del Colegio Militar. En 1912 asciende a general brigadier. Participa exitosamente en la campaña de ese mismo año contra las revueltas de Zapata, en Morelos. Se niega a reconocer a Huerta como presidente en los acontecimientos de la Decena Trágica en 1913. Forma parte de la Convención de Aguascalientes un año después, al igual que de la constitucional de 1917. Se une a Villa y gana las batallas de Torreón y Zacatecas. Tras el nombramiento de Carranza como presidente, se exilia en Estados Unidos, de 1915 a 1918. Después de su distanciamiento con Villa es traicionado por Félix Salas y entregado a los federales. Muere fusilado en 1919 (Hernández y González: 11-41).

${ }^{5} \mathrm{Al}$ respecto, basta mencionar el conjunto de festividades conmemorativas del Centenario de la Revolución y el Bicentenario de la Independencia. Creado durante el gobierno de Felipe Calderón, este programa, basado en un "discurso demagógico y retórico", no sólo incluyó la construcción de parques de atracciones, carreteras, espectáculos musicales o deportivos, sino también la publicación en los 31 estados de biografías y textos alusivos bajo el título de Serie de Cuadernos Conmemorativos. Para una mirada crítica de este programa y sus repercusiones económicas, véase Kanety Zavaleta 2010.
} 
del caudillo, aprovecha la simulación del proceso judicial para seleccionar y reforzar una visión específica de la figura del general, visión que, en la actualidad, se ha legitimado en diferentes discursos y modos de representación (literatura, historia, programas gubernamentales).

\section{Felipe Ángeles: de la periferia al centro}

Iniciaré, entonces, con el que es quizá uno de los episodios más importantes en su carrera militar: su encuentro, adhesión y colaboración en la División del Norte, comandada por Francisco Villa. Como se sabe, Ángeles fue un partidario fiel de Madero, al grado que, durante el arresto del 18 febrero de 1913 en Palacio Nacional, se negó a reconocer a Huerta. El asesinato de Madero y Pino Suárez, su aprobación de algunos postulados del Plan de Ayala de Zapata y la creciente antipatía que Carranza y otros revolucionarios comenzaban a expresar hacia Huerta, propiciaron su acercamiento a Villa:

Ángeles molesta a Huerta. Lo compara con el emperador francés: ¿Qué le habrá visto el señor presidente a este "Napoleoncito" para haberlo traído tan súbitamente? Ángeles, quien preocupaba a Huerta como jefe de las operaciones del sur, le va a molestar de igual manera por su presencia en el teatro de los acontecimientos (Guilpain 1991: 59; las cursivas son mías).

El encuentro entre ambos se produce en Ciudad Juárez, en marzo de 1914, poco después de un telegrama donde el líder de las fuerzas del norte anunciaba que "tendría verdadera satisfacción si el general Ángeles tomaba el mando de la artillería de la División del Norte" (Cervantes: 112). Con esta incorporación, Villa y su ejército logran dos victorias decisivas contra Huerta al ganar las plazas de Torreón y Zacatecas, lo que, en un corto plazo, originaría el ascenso de Carranza.

Aunque será el "heroísmo militar" lo que se pondrá de relieve en los manuales de historia cuando se refieran a este momento, como es el caso de Federico Cervantes, autor de Felipe Ángeles en la Revolución (1942), el primer trabajo biográfico conocido, ${ }^{6}$ investigadores posteriores matizarán

${ }^{6}$ Álvaro Matute, en Documentos relativos al general Felipe Ángeles, señala que Cervantes, también caudillo, conoció al general en las aulas del Colegio Militar en 
o cuestionarán este papel. Por ejemplo, Adolfo Gilly subraya su carácter burgués y su tendencia a un pesimismo político: "Ángeles no veía perspectivas a su lucha. Su visión de clase lo acercaba a Obregón [...]. La separación entre la tendencia campesina de Villa y la tendencia burguesa de Ángeles tomaba las formas de una divergencia táctico-militar" (226). En este sentido, explica que la ruptura entre ambos generales se debió no a una diferencia esencial de pensamiento - al fin y al cabo compartían su desacuerdo con toda forma de dictadura y opresión del pueblo-, sino como resultado de un distanciamiento de clase (259). ${ }^{7}$

Por su parte, Odile Guilpain, aunque no se aleja del discurso ortodoxo que reconoce su valía tanto en lo militar como en lo moral, sí plantea que cada vez más historiadores ponen en tela de juicio su ideología, particularmente con relación al interés por Estados Unidos. Su simpatía por el progreso y la cultura norteamericanas no sólo provocaron, menciona Guilpain, el rompimiento definitivo con Villa, sino también que salieran a la luz una serie de declaraciones que cuestionaban su "fidelidad" a las causas revolucionarias (1991: 83-85).

Resultado de esta ambigua relación con "El Centauro del Norte" es que surge lo que, en adelante, podríamos denominar el modelo de un Felipe Ángeles conciliador. En efecto, tras regresar de su exilio en Estados Unidos, donde "se había dedicado al estudio y había llegado a un socialismo moderado y evolucionista", el hidalguense, "con una mezcla de ingenuidad política y fatalismo", deseaba consolidar un ejército renovado que cohesionara a todas las partes en conflicto: "Ángeles proponía una reconciliación nacional que, excluyendo a Carranza, permitiera negociar con Estados Unidos el mantenimiento de buenas relaciones" (Guilpain 1991: 328; las cursivas son mías).

Los siguientes aspectos en los que me detengo tienen que ver con las representaciones que destacan su intelecto y su ética sobre la guerra. Cer-

1904, cuando éste impartía la clase de matemáticas: “lo admiró desde entonces, como matemático y militar, como ingeniero y artillero, por sus conocimientos y por sus dotes morales" (ix). También indica que, una vez que egresó del Colegio, apoyó a las fuerzas villistas y representó a Ángeles en la Convención de Aguascalientes (xiii). Esto explica, como se verá, el uso de un estilo grandilocuente en las descripciones sobre Ángeles.

7 Sobre la presencia del Estado y la burguesía en la Revolución, véase Knight 1986: 14. 
vantes, quien como vimos le profesa una gran admiración, no dudará en ofrecer un retrato casi idílico: "Fiel al recuerdo de quien fuera maestro de la juventud; del hombre modelo en quien, mejor que en los demás, descubrí no sólo cultura superior sino grandeza de alma; discípulo, amigo y jefe del Estado Mayor del único hombre completo, del superhombre contemporáneo que me haya inspirado verdadera admiración porque inculcaba ciencia y bondad" (15).

Guilpain, quien reconoce que "el afán de superación intelectual es una de las características de Ángeles y un elemento clave en su trayectoria", sitúa su exilio en Estados Unidos, de 1915 a 1918, como el periodo en el cual se privilegia su fama de pensador (2009: 3). Hay dos hechos que respaldan esto: el primero es que a partir de 1916 el combatiente "se dedica a estudiar y a participar desde Estados Unidos en la discusión del destino político de su país"; mientras que en 1917, influido por las ideas socialistas en boga, "comienza a escribir artículos" (1991: 94-95). La historiadora supone que una buena parte de estos textos debe haberse extraviado (96). Sin embargo, gracias a Cervantes, se conocen más de 10 artículos, la mayor parte de ellos publicados en revistas y periódicos norteamericanos de la época, como la Revista Mexicana, El Colmillo o La Patria, de San Antonio, Texas. Los temas que aborda reflejan bien sus intereses y personalidad: la importancia que tiene la educación en la formación de toda sociedad, la necesidad y límites de la religión, la falsedad del liberalismo, las ventajas del socialismo científico, el compromiso ético del militar y los peligros de un gobierno dictatorial.

El contenido claramente político - "Genovevo de la O", "Errores de revolucionarios y habilidades déspotas", "Opinión de Felipe Ángeles sobre Díaz, Madero y Carranza" — y moral — "Reflexiones sobre la educación", "El liberalismo es un ideal del pasado" - de estos escritos, motivaron dos tendencias en la construcción de Ángeles-pensador: por un lado, la que celebra el afán conciliador presente en sus textos, donde buscaba "la unión de todos los mexicanos contra el enemigo común" y llevar un mensaje moral a la nación "que pasa por el ennoblecimiento de la lucha y por la adopción de una resuelta actitud democrática"; y por otro, una de connotación negativa, la cual enfatiza su ineptitud política y su "traición" nacionalista al apoyar el progresismo norteamericano (Guilpain 1991: 171-172). 
Hay dos casos que ejemplifican bien esta convivencia de facetas contrarias. El primero es un artículo de Jorge Useta, publicado el 9 de julio de 1939 en Excélsior, donde lo describe no como un hombre inteligente, sino "ladino, en el sentido que damos en México a esta palabra: hermético y rencoroso" (Guilpain 2009: 2); mientras que el segundo se refiere a un fragmento de "El manifiesto de Ángeles", aparecido el 5 de febrero de 1919 en el rotativo La Patria, en el que insta a los mexicanos a no dejarse engañar por el "sentimiento antiamericano" de Carranza, sino a seguir el modelo yanqui mediante una "política de sincera amistad, de aspiración a los mismos ideales y de respeto mutuo" (Cervantes: 83).

Finalmente, me detengo en su construcción como héroe trágico. Después de tres años de exilio, se interna en Chihuahua para tratar de convencer a Villa sobre la necesidad de unificar a los revolucionarios en pos de las ideas socialistas que había asimilado en Nueva York. No obstante, el intento falla porque Villa, quien siempre se mostró receloso de todo refinamiento extranjerizante, juzga que su más brillante comandante de artillería se había pasado a filas norteamericanas: "Mi general, por lo que parece, usted se ha agringado. Mire mi general, vamos derrocando a Carranza y luego dejaremos que el pueblo resuelva por sí mismo sus destinos" (Cervantes: 379). Separados desde entonces, no se sabe muy bien cuáles fueron las actividades del excombatiente federal de 1918 a 1919, pero lo cierto es que el 15 de noviembre de este último año fue traicionado y emboscado en una cueva cercana al municipio de Balleza y conducido a Chihuahua capital. Allí, bajo las órdenes de Manuel M. Diéguez, se convocó a un Consejo de Guerra Extraordinario para juzgarlo por el delito de rebelión al gobierno constituido. Durante este juicio, evidentemente manipulado, dio muestra de sus dotes de orador al exponer con entereza sus ideas, aun sabiendo que, pasara lo que pasara, sería fusilado.

Este acontecimiento consagrará el carácter trágico del hidalguense. La primera referencia del juicio sumario la encuentro en un texto literario, Cartucho, de Nellie Campobello, publicado en 1931. En la estampa titulada "La muerte de Felipe Ángeles", una voz infantil que funciona como narradora testigo de los hechos, le asegura al lector que lo que verá, a pesar de su veracidad, no será completamente fiel: "Digo exactamente lo que más se me quedó grabado, no acordándome de palabras raras, nom- 
bres que yo no comprendí". Y, sin embargo, Campobello, con ese estilo minimalista y condensado de su primera escritura —en contraposición al lirismo afectado y sentimental de Las manos de mamá-, logra plasmar, en unas cuantas páginas, los detalles más significativos de la escena. Al inicio del texto, nos dice la narradora testigo: "yo pensé que sería un general como casi todos los villistas; el periódico traía el retrato de un viejito de cabellos blancos, sin barba, zapatos tenis, vestido con unas hilachas, la cara muy triste" ${ }^{8}$ La imagen trágica se construye, principalmente, a través de la frase reiterativa: "sé que me van a matar, QUIEREN MATARME", y la descripción escueta, pero precisa, de su fusilamiento: "Ya lo habían fusilado. Fui con Mamá a verlo, no estaba dentro de la caja, tenía un traje negro y unos algodones en las orejas, los ojos bien cerrados, la cara como cansada de haber estado hablando los días que duró el Consejo de Guerra" (95-96).

En este mismo sentido, Gilly Ilama la atención sobre la soledad en la que se encontraba el caudillo cuando es capturado y sentenciado a muerte; soledad que, en efecto, funciona como uno de los rasgos definitorios del héroe trágico: "La desubicación que parece haber sido el signo de la figura solitaria del general Ángeles, aparece hasta en la ironía de una anécdota de su ejecución. El general era ateo y se negó a recibir a un sacerdote que quiso confesarlo antes de morir" (332). Martín Luis Guzmán, en El águila y la serpiente, con la grandilocuencia literaria que caracterizó a buena parte de los escritores realistas de México, también lo pinta aislado, pero más contemplativo: "La sombra era la de un hombre gallardo. Un rayo de luz, al darle en la orilla del ala del sombrero, mordía en su silueta un punto gris [...] Por la postura comprendí que el hombre estaba absorto en la contemplación de los astros: la luz estelar le caía sobre la cara y se la iluminaba con tenue fulgor" (45). Por su parte, Odile Guilpain se dedica, hacia el final de su texto, a estudiar este comportamiento durante el juicio. Deja entrever que el fatalismo que se desprende del proceso no debe verse como uno dictado por leyes trascendentales — aunque esta visión sea, precisamente, la que impera en los discursos del mismo enjuiciado-, sino

${ }^{8}$ Como se verá más adelante, cuando aborde la teatralidad política en Felipe Ángeles, la dramaturga recupera también esta misma descripción del héroe. 
uno que obedece a un marco político específico, circunstancias históricas y juegos de poder determinados (1991: 99-101).

En estrecha relación con su carácter trágico, aparece también una faceta que, guardada la distancia, bien podría calificarse de mesiánica. Dos detalles señalados por Guilpain corroboran mi observación: el supuesto efecto "hipnótico" de sus discursos, los cuales despertaban gran emoción "en la gente, a la que le agradaba escuchar las prédicas que hacía en los lugares por donde pasaba" (97-98), y el "tono místico", casi religioso, de sus últimos escritos y homilías (129). Pese a que sus habilidades oratorias ya eran reconocidas por su labor de diplomático en Francia (cfr. Cervantes: 28) y de mediador político cuando se anexó a las huestes villistas (cfr. Gilly: 139), el militar experimentó un notorio cambio de estilo y temperamento en este año postrero de vida. Puede suponerse, como en cierto sentido lo hacen Gilly y Guilpain cuando describen su errar por la sierra Tarahumara, que entonces haya leído con asiduidad al socialista utópico Jean Jaurés, así como textos de Víctor Hugo y al polémico historiador de las religiones Jules Michelet, cuyas perspectivas y retóricas no sólo reforzarían sus propias ideas — fraternidad, ética, educación—, sino que además harían de su actitud trágica el vehículo para asumir un papel muy peculiar de redentor (Guilpain 1991: 129-30). ${ }^{9}$ Nuevamente tenemos una faceta que, al menos en apariencia, se contrapone a su formación castrense y científica, ${ }^{10}$ quien se concebía a sí mismo como agnóstico. Sin embargo, Guilpain opina que en realidad "Ángeles tenía un gran interés en la religión, había leído los evangelios, que citó durante el juicio, y respetaba profundamente las expresiones religiosas del pueblo" (1991: 146).

Aunque me ocuparé con mayor cuidado del proceso llevado en su contra durante la segunda parte del trabajo, aquí ofrezco dos muestras

\footnotetext{
${ }^{9}$ Gilly anota también al escritor francés Ernest Renan, quien llamó la atención a mediados del siglo xIx por sus controversiales obras sobre el cristianismo y la figura de Jesús: "En la inactividad de su escondite leía un libro que continuó leyendo ya capturado: la Vida de Jesús, de Ernest Renan" (331).

${ }^{10}$ Citado innumerables veces como prueba de su genialidad es el viaje que hizo en 1904 a Estados Unidos con el objetivo de comprar pólvora sin humo para el Ejército Federal, cuya empresa falló porque Ángeles, poseedor de "profundos conocimientos de matemáticas", se percató de que la fórmula química elaborada por su inventor, Hudson Maxim, era incorrecta (Cervantes: 29).
} 
extraídas de la transcripción del juicio para confirmar este afán redentor. Una pertenece al 24 de noviembre de 1919, primer día de interrogatorio, cuando exclama, entre los aplausos de los asistentes, que "mi gestión ha consistido en predicar que deben prepararse los pueblos para la democracia, que en lo futuro será un hecho, pues así lo creo" (Gobierno del Estado de Chihuahua: 152); mientras que la otra, pronunciada la tarde siguiente, reza que su defecto ha sido "amar a toda la humanidad, amar hasta a los animales, porque a veces somos nosotros más malos que ellos" (209).

Ahora bien, cabe preguntarse si la adopción de esta actitud, en un litigio perdido de antemano, fue auténtica o, al igual que los juegos de simulación de sus detractores, una estrategia sutil de amnistía. Guilpain ofrece dos respuestas: niega que haya pretendido asumirse como víctima, pero asegura que, en cambio, sí quiso crear un efecto en la concurrencia —más de cinco mil asistentes—, mediante el apasionamiento y una serie de recursos retóricos (1991: 176-78).

Para concluir este apartado, puede decirse que la figura de Felipe Ángeles ha sido objeto de distintas interpretaciones y valoraciones, las cuales han generado un doble conjunto de representaciones: aquellas que ensalzan o subrayan rasgos de su carrera militar (intelectual, conciliador, diplomático, consejero, héroe trágico) y las que atenúan o demeritan cualidades (ingenuidad política, traidor, místico, voluble, victimización). Sin embargo, y según he mostrado más arriba, algunas han sido privilegiadas de forma recurrente tanto en la propia época del caudillo (prensa) como en trabajos historiográficos y literarios posteriores (manuales, cuento, novela). Dada esta convivencia, cabe preguntarse: ¿cuáles toma en cuenta Garro para la configuración de su pieza dramática?, ¿de qué manera aprovecha los materiales históricos? Y, quizá más significativo, lo que antes podía entenderse como una pieza que critica la legitimación de un discurso basado en la demagogia y la corrupción, ¿no es ahora material aprovechable para la propaganda de un nuevo discurso que, más que "reparar" viejas afrentas, busca afianzar un determinado programa político? 


\section{La escritura de Felipe Ángeles}

Presumiblemente escrita en los cincuenta, pero publicada hasta 1967 por la extinta revista Coátl, en Guadalajara, ${ }^{11}$ la obra se aparta de los procedimientos y temas con los que habitualmente suele clasificarse a la producción dramática de Garro. ${ }^{12}$ De tipo más bien realista, esta pieza recupera un suceso histórico perfectamente identificable sin echar mano de ningún recurso vanguardista. Por el contrario, su estructura sigue los preceptos clásicos de la tragedia aristotélica: división en tres actos, desarrollo de acciones en veinticuatro horas y el recinto del Teatro de los Héroes como único lugar escénico. ${ }^{13}$

En este sentido, puede afirmarse que Felipe Ángeles se aproxima mejor, en cuanto a su tratamiento documental, a los artículos que su autora publicó entre febrero y mayo de 1968 en el semanario Por Qué, editado por Mario Méndez Rodríguez. Estos "reportajes biográficos", como ella les llamaba, describen "la acción revolucionaria y las ideas políticas de los

11 Esta revista, de muy breve duración, fue editada de 1965 al 68 por Ernesto Flores. Publicación prácticamente inconseguible — no se encuentra ni en la Hemeroteca Nacional ni en la biblioteca Daniel Cosío Villegas de El Colegio de México-, constó de sólo nueve números. En ella participaron reconocidos escritores y pintores como Francisco González León, José Emilio Pacheco, José Luis Cuevas, Salvador Novo, Juan José Arreola, Henri Michaux y Emmanuel Carballo. Para una crónica del encuentro con Juan Carlos Peredo, hijo de Ernesto Flores y la entrega de la serie completa en la FIL de 2015, véase Alv Warhol (25 de enero de 2016). "La revista Coátl" [entrada en blog, recuperada de <http://deliriosdediva.blogspot.mx/2016/01/la-revista-coatl.html>].

12 Se ha dicho muchas veces que la mayor parte de sus 16 piezas dramáticas comparten características del teatro del absurdo, el género fantástico, el realismo mágico e, incluso, el surrealismo. Para Frank Dauster, por ejemplo, "participa plenamente del concepto del teatro como comunicación poética, ilógica, y a pesar de las diferencias de técnicas y contenidos, también sería posible colocarla dentro del movimiento del llamado teatro del absurdo" (81). Para un acercamiento panorámico actual sobre su labor teatral, véase Bustamante Díaz 2008.

13 Guillermo Schmidhuber, en "Elena Garro y el teatro de realismo fantástico", apunta que la pieza en cuestión, de claro corte usigliano, corresponde al realismo de tesis; mientras Sócrates y los gatos, drama póstumo que la crítica reconoce como estrictamente histórico, pertenece al Ilamado realismo periodístico, pues recrea la matanza estudiantil del 68. Por su parte, Ute Seydel sostiene que la dramaturga se ocupó de la Revolución principalmente en sus narraciones "Nuestras vidas son los ríos" y Los recuerdos del porvenir, en las que, de forma curiosa, también se realizan juicios sumarios: en el primer caso, al general Rueda Quijano y en el segundo a Nicolás Moncada, por mandato de Francisco Rosas (79-82). 
hermanos Flores Magón, de Francisco I. Madero, el revolucionario caballero y enemigo de la violencia, de su hermano Gustavo A. Madero, de Pino Suárez, Belisario Domínguez y de los que la escritora consideraba como traidores: Victoriano Huerta y Venustiano Carranza" (Seydel: 76). ${ }^{14}$ Tanto aquellos textos como el drama que me ocupa fueron el resultado de las investigaciones que realizó, en 1953, en el archivo histórico de la Ciudadela y la Secretaría de Guerra, apoyada por el general Carlos Zapata Vela.

Dos detalles adicionales Ilaman la atención. El primero consiste en su tardía representación, once años después de que apareciera en la revista Coátl, por la compañía de la Ciudad Universitaria, bajo la dirección de Hugo Galarza. ${ }^{15}$ Se ha dicho que este silencio fue originado por su incompatibilidad con el discurso político de entonces - hay que tener presentes las revueltas agrarias en Ahuatepec, Morelos, y las huelgas ferrocarrileras-, el cual buscaba el equilibrio y la solución diplomática a los problemas sociales. Sin embargo, también puede aducirse una cierta negativa por parte del círculo de escritores en el que se desenvolvía Garro. Rosas Lopátegui incluso afirma que la influencia de Octavio Paz tuvo un peso crucial en la no siempre feliz recepción de sus dramas. Así lo confiesa Garro en una entrevista: "No la querían publicar [...] Se la leía a un grupo de escritores y me dijeron que era impublicable, e imposible de ponerla en escena" (en Rosas Lopátegui: 78).

El segundo punto que me parece relevante tiene que ver con cierta polémica en torno a su proceso de creación. Julio Aguilar, en "El enigma de Felipe Ángeles", un artículo aparecido el 29 de noviembre de 2009 en la sección "Confabulario" de El Universal, plantea dos cuestiones fundamentales: ¿la pieza se concibió en la Ciudad de México, como frecuentemente se argumenta, entre 1954 y 1956, cuando Garro regresó de Europa? o, por el contrario, ¿Octavio Paz ayudó en su escritura mientras ejercía labores

\footnotetext{
${ }^{14}$ La serie, que en un principio se denominó Los caudillos, se publicaría como libro en 1993, pero con el título de Los revolucionarios mexicanos. Como bien señala Gloria Prado en "Avatares revolucionarios: Elena Garro y su re-cuento de la historia", estas narraciones no presentan "hechos prodigiosos, mágicos, trasposiciones temporales o espaciales", sino que predomina la argumentación y la "adjetivación profusa" (88-89). Lo mismo puede decirse del texto dramático en cuestión, ya que privilegia la configuración discursiva de sus personajes.

${ }^{15} \mathrm{Al}$ año siguiente, es decir, en 1979, la UNAM lo publica en forma de libro. También se realiza una gira a Barcelona para inaugurar el Festival de Sitges.
} 
diplomáticas desde 1943 al 56, periplo en el cual lo acompañaba Garro? Aguilar se basa en una carta que Paz envió, en 1956, al traductor francés Jean-Clarence Lambert, donde le informa que ha escrito, en colaboración con Garro, una tragedia mexicana: "Posiblemente a María le interese, pues aunque se trata de un tema de la revolución mexicana, posee interés universal. Naturalmente estamos a oscuras acerca del valor de lo que hemos hecho".

Para tratar de aclarar las misteriosas líneas del poeta, el investigador emprende una serie de entrevistas a conocidos, amigos y académicos familiarizados con la producción de Garro y Paz. Entre éstos destaca Lucía Melgar, conocida especialista en la obra de la dramaturga, quien le manifestó ignorar cualquier referencia de coautoría. Por otro lado, Luz Elena Gutiérrez de Velasco, coordinadora del Centro de Estudios Lingüísticos y Literarios de El Colegio de México, simplemente le aseguró que no veía ninguna intervención de Paz, pero que "habría que hacer un estudio serio, profundo". También son reveladoras las palabras que Héctor Mendoza, el prolífico director teatral fallecido en el 2010, le dijo al articulista: "Felipe Ángeles es una obra poco teatral [...] Ésa es una obra que, en efecto, no se parece al resto de la producción de Elena; es muy diferente, pero se parece aún menos a lo que escribía Octavio Paz". Del testimonio de Emmanuel Carballo, ensayista, crítico y amigo íntimo del premio Nobel, Aguilar recoge que "quizá sí pensaron la obra entre los dos pero no creo que la escribieran juntos". Por último, logra conversar con Rosas Lopátegui y Helena Paz, quienes le manifestaron dos puntos en común: primero, que el manuscrito original está perdido y que, al parecer, Paz sí escribió las escenas de los generales, pero Garro tuvo que enmendarlas. Aguilar concluye, pues, que el camino para un estudio concienzudo sobre la enigmática génesis de la obra apenas ha comenzado.

\section{Garro y la teatralidad política: hacia una imagen de Felipe Ángeles}

Pensar los textos dramáticos como complejas construcciones de ideas e imágenes que tienden a legitimarse en función del dramaturgo, la competencia cultural del espectador/lector y los códigos sociales de una época 
no sólo permite una evaluación operativa de los signos y discursos que los conforman, sino también un acercamiento más actual del papel que una pieza tiene en un momento concreto para un grupo receptor específico.

De acuerdo con lo anterior, Juan Villegas Ilama la atención sobre tres aspectos: la configuración de un imaginario, real o virtual, de los textos dramáticos (33); la posibilidad de que ese imaginario se legitime a través de los discursos culturales de un país (61) y el concepto de teatralidad social como la descripción de conductas y gestualidades premeditadas en distintos ámbitos de una sociedad: teatralidad política, deportiva, religiosa, pedagógica (50).

En efecto, el juicio sumario esbozado en el drama se caracteriza por el comportamiento estudiado de sus participantes; comportamiento que, si bien responde a los protocolos de un proceso jurídico de tipo extraordinario, también supone la planificación de un grupo que busca erigirse con el poder: "Señores defensores: el Consejo que tengo el honor de presidir quiere demostrar al pueblo que no ha recibido consignas [...] y yo declaro por mi honor que no venimos en el deseo de matar a este señor" (Gobierno: 149), exclama el Presidente del Consejo en la transcripción original, mientras que Garro pone en boca del general carrancista Diéguez que: "tenemos listos testigos y testimonios. El juicio debe ser rapidísimo [...] no es un juicio militar, sino político" (42).

Garro aprovecha esta teatralidad en dos sentidos: por un lado, destacando su carácter de simulación, a través de diálogos como el del primer acto, donde los generales que conforman el Consejo de Guerra expresan versiones contrastantes de Ángeles (16), o mediante la ironía, ya sea metateatral: "Escobar. Ahora me explico por qué vamos a juzgarlo en un teatro... a mí me cuesta aprenderme los papeles de memoria" (17); "Me quedo hasta el final de esta función de teatro" (56), o literaria: "LÓPEZ HeRMOSA. Disculpe el señor Agente del Ministerio Público, ya que no eran mis intenciones lastimarlo, y en obsequio a su deseo retiro las palabras que le hirieron. Agente. Queda borrada la mala impresión" (29); "EsCOBAR (riéndose). ¡Pues en este juicio hay muchas palabras porque hay muy pocos hechos!" (45).

Al revisar el escrito taquigráfico, advierto que esta conversación entre los generales Gavira, Escobar, Bautista, Acosta, García y Peraldo es ficcio- 
nal, en tanto que el tono fársico, de burla, sí está presente en el personaje de Félix Salas, quien propició la captura: "Presidente. Su estado. Salas: 'Horita' estoy bien. (Risas generales). Presidente. No, diga si es casado o soltero" (Gobierno: 175) y "ÁNGELES. Pues eso es una mentira, pues teniendo con qué defenderme no me hubiera rendido y mejor hubiera perecido. SAlas: Entonces cómo está aquí... (Con sorna. Risas del público.)" (189). Garro critica esta teatral y ambivalente actitud del público —por una parte, entusiastas seguidores de Ángeles, por otra, risueños participantes de un espectáculo político- mediante la figura desencantada de Manuel M. Diéguez, quien comprende y ejecuta la lógica del poder: “¡No me hable de la gente! Dentro de unas horas les mataremos a Felipe Ángeles y no moverán un dedo para salvarlo. El Primer Jefe les regala esa imagen sacrificada, en la que ellos se ven ejemplares" (27).

En relación con esto, Villegas afirma que una de las funciones de las teatralidades en un texto dramático — aquí, la política— es la de transmitir un mensaje que legitime un sistema de valores (61). Garro juega con el término verdad política para subrayar aún más el cálculo de las actuaciones: "DiÉGuez. Y sin embargo, Escobar, la verdad en la política son los hechos consumados" (48), y "Reconozco también que hay actos que no me gustaría cometer y que no tengo más remedio que realizar" (56).

Puesto que toda teatralidad social involucra un conjunto de individuos que se comunican mediante códigos de comportamiento y signos visuales, resulta importante señalar la disposición en el vestuario y la escenografía, toda vez que constituyen "el modo cómo el político quiere ser visto en el escenario de la sociedad o de la historia" (Villegas: 67). Aunque el interior del teatro no se menciona en la transcripción taquigráfica, supongo que la descripción que Garro acota en su texto debe ser real, pues corresponde con los tapices interiores del edificio en la actualidad: "El vestíbulo del teatro debe tener candiles de cristal, muros tapizados de seda roja, espejos de marcos dorados y bancos laterales de terciopelo rojo" ${ }^{16}$ En cuanto a la vestimenta de los personajes, ésta corresponde, como es natural, a una de

16 El Teatro de los Héroes en el que tuvo lugar el juicio se incendió en 1955. Fundado el 16 de septiembre de 1902 y diseñado por el arquitecto George E. King era un edificio de estilo victoriano, entonces muy en boga en el país. El recinto moderno, inaugurado por el presidente José López Portillo el 2 de octubre de 1980, se encuentra 
tipo militar, aunque el juicio más bien sea político. Garro no se ocupa demasiado en ello, pues supone que sus lectores/espectadores se encuentran familiarizados con estos tópicos. En cambio, sí remarca la apariencia del sentenciado, al recuperar la misma descripción histórica que Campobello empleó cuando fue puesto a disposición del tribunal: "Viste una camisa vieja y unos pantalones viejos de mezclilla desteñida. Calza unos zapatos de tennis muy gastados. Lleva dos libros bajo el brazo. Es moreno, delgado y alto"; "trataba de presentarme limpio en los combates" (69) y "Vistiendo el mismo traje con que arribó a esta ciudad — pantalón de mezclilla—, zapatos de lona blancos que le fueron obsequiados, y pulcramente peinado y afeitado" (107). ${ }^{17}$

Aunque Garro la omite, hay otra alusión al significado social de la indumentaria en el discurso histórico del protagonista, cuando confiesa que:

siempre he visto que las ropas influyen mucho en ciertas circunstancias; esto me preocupaba relativamente porque quería presentarme algo mejor de como estoy; pero ya que no se puede, a este punto no le doy mucho interés, ya que no he tenido oportunidad para presentarme ante el pueblo que me ve tan mal vestido como ando (Gobierno: 126).

Ahora bien, ¿cómo se perfila la figura de Felipe Ángeles sobre este fondo de teatralidad política?, ¿cuáles facetas, de las que hemos visto propagadas por la historia, la literatura o la prensa, retoma Garro?; ¿su texto, que en un principio buscó la reivindicación del general oponiéndose a las decisiones gubernativas de entonces, no ha contribuido ya a legitimar el discurso político presente?

No creo descabellado argüir que, en Felipe Ángeles, Garro toma una perspectiva maniquea del hecho histórico: el lado "correcto", representado en el trascendentalismo ético del militar, de cierta filiación idealista; y el "incorrecto", simbolizado en el cálculo concreto, amoral, estrictamente político de Venustiano Carranza, el Primer Jefe. Sobre esta oposición, en la

en el mismo sitio que su antecesor (México es cultura. La cartelera nacional, Secretaría de Cultura, <www.mexicoescultura.com $>$ ).

17 Cabe destacar que en el hecho histórico Ángeles compartió el juicio con Néstor Enciso de Arce, del Batallón de Infantería, y Antonio Trillo, un adolescente de 17 años que lo seguía por la sierra Tarahumara. Ambos fueron absueltos de sus cargos. 
que el resto de los personajes parecen funcionar más como índices positivos (las señoras Revilla, Seijas y Galván, los abogados Gómez Luna y López Hermosa) o negativos (Gavira, Diéguez, Salas, Víctores Prieto, Presidente del Consejo, Escobar), la dramaturga realizará, a partir del discurso auténtico registrado en los archivos históricos, su propia "tipificación" del general.

Una de las primeras estampas que Garro destaca es la del héroe trágico, principalmente en las dos facetas que ya señalé en el apartado inicial: la fatalista y la redentora. Por ejemplo, en el segundo acto, donde se desarrolla el interrogatorio y defensa del caudillo, éste exclama: "Señores, está bien que me maten, ya que soy un testigo inoportuno de su triunfo" (34) y "Declaro solemnemente que no creo que por perversidad se tengan para conmigo malas intenciones, sino que sólo se me juzga con la pasión de la política" (39). Al comparar este parlamento con la transcripción, vemos su similitud: "Declaro solemnemente que, como antes dije, no juzgo que perversamente se tenga para conmigo malas intenciones; sé bien que cuando elementos distinguidos juzgan a quien se halla en el banquillo, debe respetarse su gestión, y yo me creo limpio de toda culpa" (Gobierno: 209). En sintonía con este fatalismo, Garro introduce algunas reflexiones sobre la memoria y la historia: "ÁNGELES. Ahora, después de este fracaso, entre todos, quizás podríamos inventar la historia que nos falta" (52); "DiéGuez. La historia es una puta, general. No hay que fiarse de ella" (19), "Quiere dejarnos su vida y su muerte como uno de esos planos de batallas célebres, bien trazados, y cada trozo con una explicación, para que mañana se pueda leer" (44) o "Los hechos existen en relación con los demás. Un hecho no es algo aislado. Tiene múltiples aspectos y consecuencias imprevisibles, aun para el que lo comete" (49).

En contraposición, tanto en el discurso real de Diéguez — quien sólo cuenta con unas pocas intervenciones de carácter protocolario- como en el de Ángeles, el tema de la historia apenas y se menciona. Descolla, no obstante, este pasaje: "Es que nuestros poetas pintan las cosas de una manera exagerada; los poetas relatan la Batalla del 5 de mayo de una manera perjudicial para los niños que se inician en el estudio de la historia patria y perjudicial para nuestras relaciones con Francia" (Gobierno: 145).

El redencionismo de Ángeles, imbuido de cierto lirismo, queda patente hacia el tercer acto, cuando en la penumbra de su celda, predica a Esco- 
bar: "lo único que deseo es que hablen todos, que se oiga la voz del hombre" (Garro: 65) o, al despedirse de su familia, "Dígales que yo no muero porque mi patria me repudie, sino por un exceso de amor entre ella y yo [...] Dígales que no olviden el color de su luz, ni sus montañas infinitas, tan caminadas por su padre" (70). Por su parte, el texto taquigráfico reproduce: "Ese ha sido mi defecto, amar a todos los mexicanos, y es más, amar a toda la humanidad, amar hasta a los animales, porque a veces somos nosotros más malos que ellos" (Gobierno: 209) o "Mi gestión ha consistido en predicar que deben prepararse los pueblos para la democracia, que en lo futuro será un hecho, pues así lo creo" (152).

Otros aspectos que Garro somete a tratamiento son, precisamente, aquellos que tienen que ver con sus cualidades morales e intelectuales. En el primer acto, Diéguez puntualiza: “El mundo entero pide clemencia para Felipe Ángeles, el gran matemático, el gran estratega, el maestro" (11) y "AGENTE. ¡Felipe Ángeles no es un acusado cualquiera, ya que goza de una inteligencia superior y es esta inteligencia suya su arma más peligrosa!" (37). Asimismo, en el segundo acto se abordan sus convicciones éticas:

Dominado por la fraternidad conviví con los revolucionarios y cuando la Revolución se dividió en dos bandos, uno el ganancioso y otro el que renunció al poder personal en el nombre de las ideas por las cuales habíamos peleado todos, yo me uní a estos últimos, ya que no creo en la ambición personal (41).

Sin embargo, en la transcripción del juicio, su discurso adquiere un tono más agresivo: "La fraternidad se conquista a fuerza de sangre; los ricos no quieren que las cosas dejen de ser como son; quieren que sean siempre las mismas, sin fijarse en las miserias del pobre" (Gobierno: 142).

Las referencias a su papel conciliador también ocupan un lugar en el texto dramático. Al inicio del segundo acto, Felipe Ángeles justifica, ante el fiscal, las razones que lo hicieron regresar de Estados Unidos: "Repito que desde mi vuelta a México, no he combatido. Yo, señores, no hice la Revolución para que tuviera este final de asesinatos, sino la concordia y la igualdad de los mexicanos" (32-33). Sin embargo, la versión taquigráfica abunda un poco más en su relación con el Centauro: "Como lo he dicho antes, la misión que yo traje fue de conciliación; fue de aconsejar a Villa porque Villa es bueno en el fondo; a Villa lo han hecho malo las circuns- 
tancias, los hombres y las injusticias; eso es lo que me ha perjudicado quizá" (Gobierno: 125-126).

Dos reflexiones del último acto, una sobre la peculiar naturaleza del lenguaje como permanencia y la otra acerca de la circularidad del tiempo, configuran su faceta de filósofo: "Nada existiría si antes no le hubiera dado forma la palabra. Si muero será por las palabras, por las palabras que no se lleva el viento, compañero" (65) y, más adelante: "El tiempo, el tiempo, siempre el tiempo... Quizás, coronel, el tiempo nuestro se ha gastado y empieza ahora un tiempo nuevo" (59).

Por el contrario, en el texto taquigráfico no se anota ningún discurso de tipo filosófico, aunque sí acota el transcriptor que la noche anterior a su fusilamiento, en la prisión del cuartel del 21 Regimiento de Caballería de Chihuahua —el héroe garriano permanece en el camerino del Teatro-, conversó con el sacerdote Valencia sobre "religión, viéndola el señor Ángeles desde el punto de vista filosófico, en cuya materia se reveló un gran erudito" (Gobierno: 218).

Para terminar, me detengo en el soliloquio previo a su ejecución, porque se trata del discurso que mejor ilustra tanto la pasión retórica del último Felipe Ángeles como el lirismo de Garro:

Nadie te entiende Felipe Ángeles. ¡Mírate ahí!, tumbado en el catre de los fusilados [...] Debajo de ese cielo había mi casa; había mi padre; había mi patria Ilamándome: ¡ven aquí, niño Felipe Ángeles, no escapes a la ardua tarea de darme forma! [...] ¡Yo galopo, yo batallo, yo Iloro al ver llorar al hombre que me sigue en la noche! [...] ¡Allí en un rincón está mi madre mirando un papalote! [...] ¡Llora Felipe Ángeles! ¡Llora por ti, antes de que tus lágrimas desaparezcan de esta tierra regada por las lágrimas! [...] Madero era un tonto, Ángeles era un tonto. De las lágrimas de los tontos nacen manantiales de los que surge la frescura de la patria (68).

\section{Conclusiones}

Como he intentado mostrar en este ensayo, la multiplicidad de facetas históricas que existen sobre el personaje no sólo condiciona la forma en que se percibe una figura determinada, sino que además estimulan una valoración contrastante. En el caso de Felipe Ángeles, al hacerse cargo únicamente de la última etapa en la vida del general —el juicio sumario 
y su fusilamiento-, Garro emplea la ironía y la teatralidad política de los materiales documentales para enfatizar la actuación eminentemente trágica que desempeñó en el tribunal.

Algunas veces con modificaciones estructurales (el general Bautista es creación de Garro, lo mismo que los apellidos de las tres señoras del Comité Pro-Ángeles; mientras que omite a dos médicos que estuvieron en el juicio, a Trillo y a Néstor) o de estilo (resulta evidente el tratamiento lírico del lenguaje) y otras veces casi fiel a las fuentes, lo cierto es que la dramaturga privilegia una imagen heroica en las dimensiones que ya vimos, pero ligeramente idealizada por la oposición tajante entre buenos y malos que impera en el texto.

Aunque este planteamiento pudo ser, para un lector de hace cincuenta años, una fuerte, e incluso peligrosa crítica al discurso oficial, hoy parece menos contestarario debido a que programas culturales del gobierno, como el implementado por Felipe Calderón en el 2010, ya contemplan en su agenda de héroes revolucionarios la figura de nuestro protagonista, mediante la producción de biografías, monumentos y puestas en escena del texto garriano. ${ }^{18}$ Otra razón más la encuentro en el propio ámbito literario, a través de las publicaciones de Ignacio Solares, La noche de Ángeles (1991) o la novela gráfica Pancho Villa toma Zacatecas, de Paco Ignacio Taibo II, en donde la figura en cuestión tiene el mismo protagonismo que Villa. Finalmente, con la expansión de la web, hoy en día existen multitud de blogs, foros y sitios de Internet auspiciados por el propio gobierno mexicano, en los que se "rinde culto" y admite la heroicidad del caudillo. ${ }^{19}$

En resumen, y sin dejar de reconocer el valor literario y crítico que el texto de Garro tuvo en su momento, verdad es que la figura del general Felipe Ángeles revela que el vaivén del tiempo y los procesos culturales, condicionan la mirada de una sociedad.

18 Por ejemplo, la cartelera del Teatro Itinerante, en la Región de los Ríos, Tabasco, tiene en su lista la obra de Garro desde el 2005.

19 Al respecto, me llaman la atención dos sitios que contienen información muy completa y actualizada: la página $<w w w$.memoriapoliticademexico.org $>$, una extensa base de datos con biografías de personajes mexicanos ilustres y el blog <generalfelipe angeles.blogspot.mx>, que contiene textos históricos, fotografías, cartas, videos, homenajes y enlaces multimedia. 


\section{Bibliografía}

Aguilar, Julıo. "El enigma de Felipe Ángeles", en Confabulario de El Universal (29 de noviembre de 2009). Artículo en línea disponible en <http://confabulario. eluniversal.com.mx/el-enigma-de-felipe-angeles $>$.

Bustamante Díaz, Gerardo. "Elena Garro: cincuenta años de dramaturgia", en Revista Casa del Tiempo. México. I (abril de 2008): 59-61.

Campobello, Nellie. Cartucho. México: Era, 2000.

Certeau, Michel de. La escritura de la historia. México: Universidad Iberoamericana, 1993.

Cervantes, Federico. Felipe Ángeles en la Revolución. Hidalgo: Servicios de Comunicación Empresarial, 2008.

Dauster, Frank. "El teatro de Elena Garro: evasión e ilusión", en Revista Iberoamericana. Pittsburgh. XXX (enero de 1964): 81-89.

Garro, Elena. Felipe Ángeles. México: Universidad Nacional Autónoma de MéxiCO, 1979.

Gilly, Adolfo. La revolución interrumpida. México: Era, 1994.

Gobierno del Estado de Chinuahua. Felipe Ángeles "El legado de un patriota." Textos del juicio y ejecución de un idealista revolucionario. Chihuahua: Programa Editorial del Gobierno del Estado, 2003.

GuILPAIN, ODILE. Felipe Ángeles y los destinos de la Revolución mexicana. México: Fondo de Cultura Económica, 1991.

GuILPAIN, ODILE. "El general Felipe Ángeles: humanismo y educación militar", en Revista de Estudios Históricos de INAH. México. LXXIV (septiembre, 2009): 67-80.

GuZMÁn, MARTín Luis. El águila y la serpiente. México: Porrúa, 1995.

Hernández y Lazo, Begoña y Ramiro González. Felipe Ángeles. Serie de Cuadernos Conmemorativos. México: Instituto Nacional de Estudios Históricos de la Revolución Mexicana, 1985.

IgGers, GeORGe. La ciencia histórica en el siglo Xx. Barcelona: Labor, 1995.

Kanety Zavaleta, Sandra. "A cien años de la Revolución... inconclusa", en México a 100 años de su Revolución. Selección de Elisa Gómez. México: Consejo Nacional para la Cultura y las Artes, 2010. 18-21.

KNIGHT, Alan. "La Revolución mexicana: ¿burguesa, nacionalista o simplemente gran rebelión?", en Cuadernos Políticos. México. XLVIII (octubre, 1986): 5-32.

Matute, Álvaro. Documentos relativos al general Felipe Ángeles. México: Domés, 1982.

Melgar, Lucía. Elena Garro. Lectura múltiple de una personalidad compleja. Puebla: Benemérita Universidad Autónoma de Puebla, 2002.

Prado, GloriA. "Avatares revolucionarios: Elena Garro y su re-cuento de la historia", en Elena Garro: recuerdo y porvenir de una escritura. Selección de Luz Elena Gutiérrez de Velasco y Gloria Prado. México: Consejo Nacional para la Cultura y las Artes, 2006. 87-100.

Rosas lopátegui, Patricia. El asesinato de Elena Garro. Periodismo a través de una perspectiva biográfica. México: Porrúa, 2005.

Schaff, Adam. Historia y verdad. Ensayo sobre la objetividad del conocimiento histórico. México: Grijalbo, 1982. 
Seydel, UTE. "Felipe Ángeles: la reivindicación de la soberanía del Yo", en Literatura Mexicana. XXI-2 (2010): 75-90.

SChmidhuber, Guillermo. Dramaturgia mexicana: fundación y herencia. Guadalajara: Universidad de Guadalajara, 2006.

Villalobos, RebeCA. "Comentarios y bibliografía sobre la historiografía de Leopold von Ranke", en Revista de Estudios Históricos del INAH. México. LXVI (2007): 129-134.

Villegas, Juan. Para la interpretación del teatro como construcción visual. California: Ediciones Gestos, 2010.

Jesús Manuel Gamboa Valles

Es egresado de la Licenciatura en Literatura Hispanomexicana y la Maestría en Estudios Literarios de la Universidad Autónoma de Ciudad Juárez. Ha impartido clases de Lectura y Redacción en esa misma institución. Cuenta con publicaciones en el Centro de Investigación y Documentación Dramática Norteatro, la Revista de Literatura Mexicana Contemporánea de UTEP ("Símbolo y psicoanálisis: Una aproximación a Los recuerdos del porvenir de Garro", 41, abril-junio de 2009) y la antología Al norte: estudios de literatura ("Entre el crítico y el poeta: la forma como principio estético en Jorge Cuesta"), de próxima aparición. 